\title{
Novel Antibiotic-loaded Point-of-care Implant Coating Inhibits Biofilm
}

\author{
Jessica Amber Jennings PhD, Daniel P. Carpenter BS, Karen S. Troxel PhD, \\ Karen E. Beenken PhD, Mark S. Smeltzer PhD, Harry S. Courtney PhD, \\ Warren O. Haggard PhD
}

Published online: 21 January 2015

(C) The Association of Bone and Joint Surgeons (B) 2015

\begin{abstract}
Background Orthopaedic biomaterials are susceptible to biofilm formation. A novel lipid-based material has been developed that may be loaded with antibiotics and applied as an implant coating at point of care. However, this material has not been evaluated for antibiotic elution, biofilm inhibition, or in vivo efficacy.
\end{abstract}

\footnotetext{
The institutions of one or more of the authors (JAJ, DC, KB, MS, $\mathrm{HSC}, \mathrm{WOH})$ have received, during the study period, funding from Biomet, LLC (Warsaw, IN, USA). One author (KT) is an employee of Biomet, LLC.

All ICMJE Conflict of Interest Forms for authors and Clinical Orthopaedics and Related Research ${ }^{\mathbb{R}}$ editors and board members are on file with the publication and can be viewed on request.

Clinical Orthopaedics and Related Research ${ }^{\mathbb{R}}$ neither advocates nor endorses the use of any treatment, drug, or device. Readers are encouraged to always seek additional information, including FDAapproval status, of any drug or device prior to clinical use. Each author certifies that his or her institution approved the animal protocol for this investigation and that all investigations were conducted in conformity with ethical principles of research.
}

J. A. Jennings ( $\square)$, D. P. Carpenter, W. O. Haggard Department of Biomedical Engineering, University of Memphis, 330 Engineering Technical Building, Memphis, TN 38152-3210, USA

e-mail: jjnnings@memphis.edu

\section{K. S. Troxel}

Biomet, Warsaw, IN, USA

\section{K. E. Beenken, M. S. Smeltzer}

University of Arkansas for Medical Sciences, Little Rock, AR, USA

\section{H. S. Courtney}

University of Tennessee Health Science Center, Veterans Affairs Medical Center, Memphis, TN, USA
Questions/purposes (1) Do antibiotic-loaded coatings inhibit biofilm formation? (2) Is the coating effective in preventing biofilm in vivo?

Methods Purified phosphatidylcholine was mixed with $25 \%$ amikacin or vancomycin or a combination of $12.5 \%$ of both. A 7-day elution study for coated titanium and stainless steel coupons was followed by turbidity and zone of inhibition assays against Staphylococcus aureus and Pseudomonas aeruginosa. Coupons were inoculated with bacteria and incubated 24 hours $(\mathrm{N}=4$ for each test group). Microscopic images of biofilm were obtained. After washing and vortexing, attached bacteria were counted. A mouse biofilm model was modified to include coated and uncoated stainless steel wires inserted into the lumens of catheters inoculated with a mixture of $S$ aureus or $P$ aeruginosa. Colony-forming unit counts $(\mathrm{N}=10)$ and scanning electron microscopy imaging of implants were used to determine antimicrobial activity.

Results Active antibiotics with colony inhibition effects were eluted for up to 6 days. Antibiotic-loaded coatings inhibited biofilm formation on in vitro coupons (log-fold reductions of $4.3 \pm 0.4$ in $S$ aureus and $3.1 \pm 0$ for $P$ aeruginosa in phosphatidylcholine-only coatings, $5.6 \pm 0$ for $S$ aureus and $3.1 \pm 0$ for $P$ aeruginosa for combinationloaded coatings, $5.5 \pm 0.3$ for $S$ aureus in vancomycinloaded coatings, and $3.1 \pm 0$ for $P$ aeruginosa for amikacinloaded coatings $(\mathrm{p}<0.001$ for all comparisons of antibiotic-loaded coatings against uncoated controls for both bacterial strains, $\mathrm{p}<0.001$ for comparison of antibioticloaded coatings against phosphatidylcholine only for $S$ aureus, $\mathrm{p}=0.54$ for comparison of vancomycin versus combination coating in $S$ aureus, $\mathrm{P}=0.99$ for comparison of antibiotic- and unloaded phosphatidylcholine coatings in $P$ aeruginosa). Similarly, antibiotic-loaded coatings reduced attachment of bacteria to wires in vivo (log-fold 
reduction of $2.54 \pm 0 ; \mathrm{p}<0.001$ for $S$ aureus and $0.83 \pm 0.3 ; \mathrm{p}=0.112$ for $P$ aeruginosa).

Conclusions Coatings deliver active antibiotics locally to inhibit biofilm formation and bacterial growth in vivo. Future evaluations will include orthopaedic preclinical models to confirm therapeutic efficacy.

Clinical Relevance Clinical applications of local drug delivery coating could reduce the rate of implant-associated infections.

\section{Introduction}

Musculoskeletal trauma often requires implanted biomaterials for fixation or joint replacement that are susceptible to biofilm formation, which can lead to persistent infections $[11,65,68]$. The primary strategy for prevention is aseptic surgical technique followed by prophylactic systemic administration of antibiotics [28, 71]. Antiinfective biomaterials are increasingly used as an adjunctive strategy to prevent implanted biomaterial infections and to inhibit biofilm-forming microorganisms $[13,27,44,49,55,63$, 64]. Commonly used local antibiotic delivery systems range from antibiotic-loaded bone cement to calcium-based drug delivery systems to sprinkling antibiotics within the wound site [8, 24, 40, 42]. Recent developments have been focused on degradable and customizable local delivery strategies to ensure coverage of the wound, effective antibiotic elution, and minimization of secondary procedures $[15,30,60]$. These local delivery strategies include degradable sponges [50], injectable biomaterials [48, 53, 80], and coatings of antimicrobial molecules on implanted surfaces $[25,30,43,66]$. These materials vary in degradation rate and elution profile of antimicrobials and may require prefabrication to attach antimicrobial molecules or coating materials to implant surfaces.

We have developed a novel phosphatidylcholine-based material that can be loaded with antibiotics and applied as a coating on implants at point of care, acting as an "antibiotic crayon." Here we provide the initial description of the antibiotic-loaded lipid-based material, which is advantageous because of its ability to be applied to the entire implant surface with clinician-selected antibiotics and its potential to elute antibiotics and prevent biofilm formation over time. Although antibiotics have been incorporated into phosphatidylcholine coatings, antibiotic elution and efficacy in inhibiting biofilm-based microorganisms have not yet been characterized.

The primary question we posed for our study was whether lipid-based carriers elute active antibiotics in vitro and in vivo to inhibit biofilm formation on metal substrates. Additionally, is the antibiotic-loaded coating effective in preventing biofilm formation in an in vivo model of polymicrobial biofilm?

\section{Materials and Methods}

We evaluated coatings with and without antibiotics for antimicrobial activity in vitro and in vivo compared with uncoated controls (Fig. 1).

\section{Fabrication and Coating}

Four types of coatings were fabricated by mixing $6 \mathrm{~g}$ of Phospholipon 90G (Lipoid Gmb, Ludwigshafen, Germany) and $2 \mathrm{~g}$ of antibiotic in the following four groups: $25 \%$ amikacin-loaded (Group A), 25\% vancomycin-loaded (Group V), combination of $12.5 \%$ amikacin and $12.5 \%$ vancomycin-loaded (Group AV), unloaded phosphatidylcholine (Group P), and uncoated controls (Group U). Through a process of warming to $37^{\circ} \mathrm{C}$ and kneading powdered antibiotics into Phospholipon 90G, a uniform mixture of powdered antibiotics and phosphatidylcholine was obtained for each experimental group. In preliminary formulation experiments, $25 \%$ of powdered antibiotic was selected as the loading percentage because consistency of the coating was negatively affected at concentrations higher than this amount. For formulations with dual antibiotics, $25 \%$ of total antibiotic was incorporated by mixing $12.5 \%$ of each. After loading into open-ended syringes, materials were sterilized by low-dose $(25 \mathrm{kGy})$ gamma irradiation. Titanium coupons (19-mm diameter; Ti-6Al4V Grade 5) and stainless steel coupons (17-mm diameter; 316L stainless steel) were machined and sanded with 100, 220, 400, 800, and 1000 grit sandpaper to a uniform finish. The coupons were then washed with dish soap, sonicated for 5 minutes in $20 \mathrm{~mL}$ of phosphate-buffered saline (PBS) to remove any leftover residual particulates, and autoclaved at $121^{\circ} \mathrm{C}$ for sterilization. Coupons were coated with each one of the three types of antibiotic coatings by exposing solid material by depressing the plunger of the open-ended syringes and manually applying the mixtures until all surfaces were visibly coated and the uncoated coupons served as controls.

\section{Elution and Eluate Activity Studies}

Coupons were placed in 12-well cell culture plates with $2 \mathrm{~mL}$ of PBS. Samples were taken and the medium was refreshed each day for 7 days. Concentration of vancomycin in eluates was determined by measuring absorbance at $270 \mathrm{~nm}$ with a BioTek Synergy $\mathrm{H} 1$ plate reader (BioTek, 


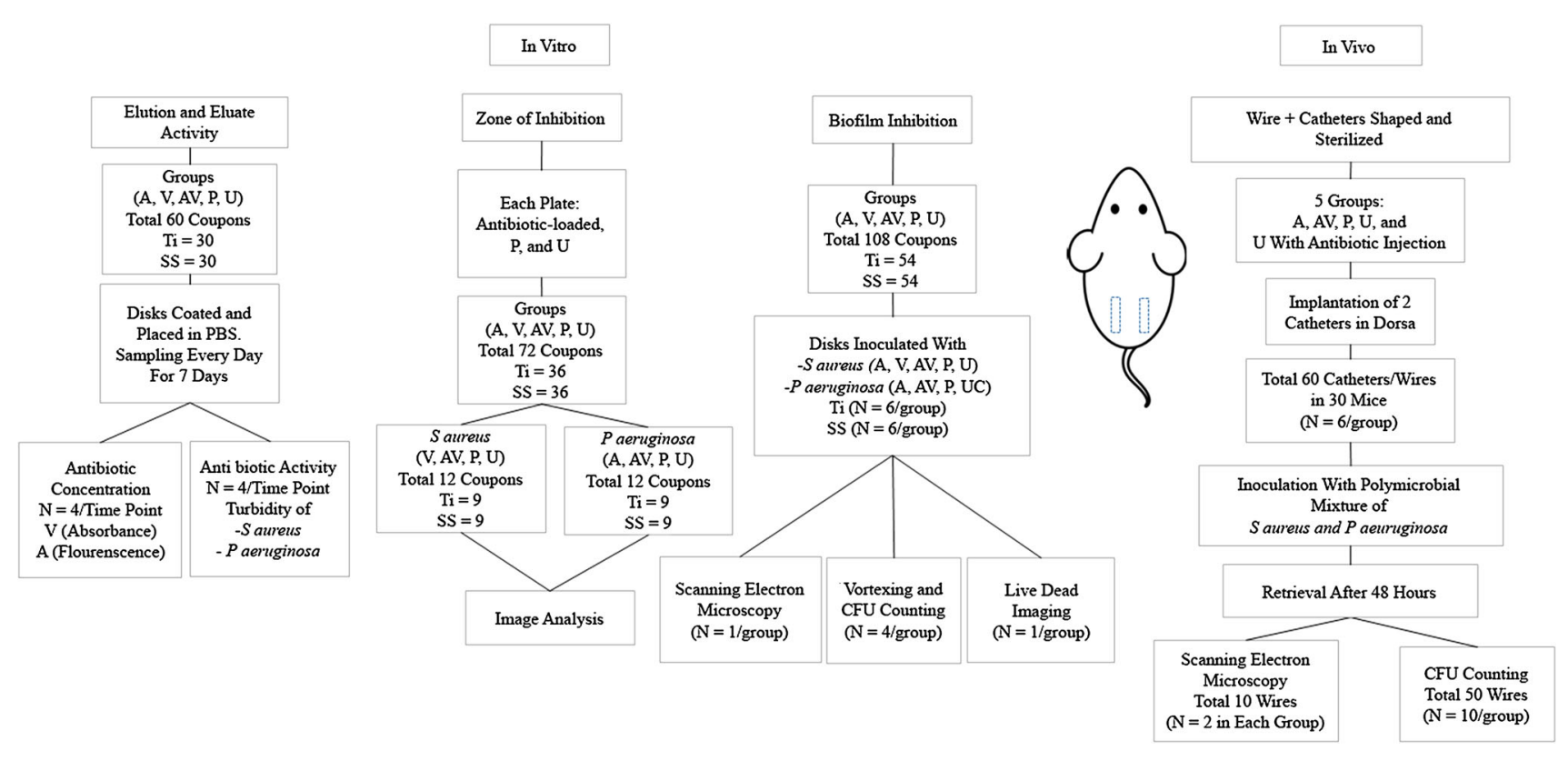

Fig. 1 Diagram shows the experimental design.

Winooski, VT, USA) [72]. Concentration of amikacin in eluates was determined by reacting 10 -fold diluted samples with a mixture of acetylacetone and formaldehyde in a buffer solution of boric acid, acetic acid, and phosphoric acid at pH 2.7 and boiling for 20 minutes. Fluorescence of the reacted product was measured at $471 \mathrm{~nm}(410 \mathrm{~nm}$ excitation) with a BioTek Synergy plate reader [46]. All concentrations were normalized to standard curves of known concentrations of antibiotics. Eluates were diluted $1: 10$ in $5-\mathrm{mL}$ tubes with $1.75 \mathrm{~mL}$ of tryptic soy broth (TSB), $200 \mu \mathrm{L}$ of eluate, and inoculated with $50 \mu \mathrm{L}$ of Staphylococcus aureus (UAMS-1 strain) or Pseudomonas aeruginosa (PA01) at approximately $1 \times 10^{6}$ colonyforming units $(\mathrm{CFUs}) / \mathrm{mL}$. After overnight incubation, absorbance was determined at $530 \mathrm{~nm}$ as an indicator of planktonic bacterial growth.

\section{Zone of Inhibition Studies}

Titanium and stainless steel coupons were coated as described previously. One set of Petri dishes was inoculated with $1 \times 10^{5}$ CFUs of $S$ aureus, and another set was inoculated with $P$ aeruginosa. One coupon each of antibiotic-loaded coated groups was placed on plates with controls groups of $\mathrm{P}$ and $\mathrm{U}$. Coatings $\mathrm{V}$ and $\mathrm{AV}$ were placed with $\mathrm{P}$ and $\mathrm{C}$ controls on each plate of $S$ aureus. One coupon of each coating (A, AV, P, or C) was placed on plates inoculated with $P$ aeruginosa. Each set of antibiotics and controls was placed on three separate replicate plates. Zones of inhibition were imaged and the diameters measured using Image $\mathbf{J}$ software (National Institutes of Health, Bethesda, MD, USA).

In Vitro Biofilm Inhibition

From preliminary studies and reports in the literature [9], it was determined that a modified TSB, containing $0.5 \%$ glucose and $3 \%$ salt, would be used as the biofilm medium for $S$ aureus to improve consistency. Coated coupons and controls were placed into wells of 12-well plates and inoculated with $10^{6} \mathrm{CFUs}$ of either $S$ aureus or $P$ aeruginosa in biofilm media and TSB, respectively. After overnight growth, bacterial media were removed from the wells and washed gently twice with PBS to remove any planktonic cells. One coupon from each group was then carefully removed so as not to disturb the biofilm and stained with FilmTracer live/dead stain (Invitrogen, Eugene, OR, USA) to visualize patterns of live and dead bacterial cell attachment. Another coupon from each group was also removed and placed in fixative for imaging with a scanning electron microscope. Fixed biofilm samples on coupons were washed several times in phosphate buffer, postfixed in $1 \%$ osmium tetroxide in phosphate buffer, and rinsed. Biofilm was en bloc stained with $2 \%$ uranyl acetate, rinsed with deionized water, dehydrated in ethanol, and dried using a critical point dryer [32]. Coupons were mounted, biofilm side up, onto standard electron microscopy stubs that were coated with double-sided, carbon black sticky tabs. Specimens were conductively coated before imaging with a thin sputtercoating of gold- 

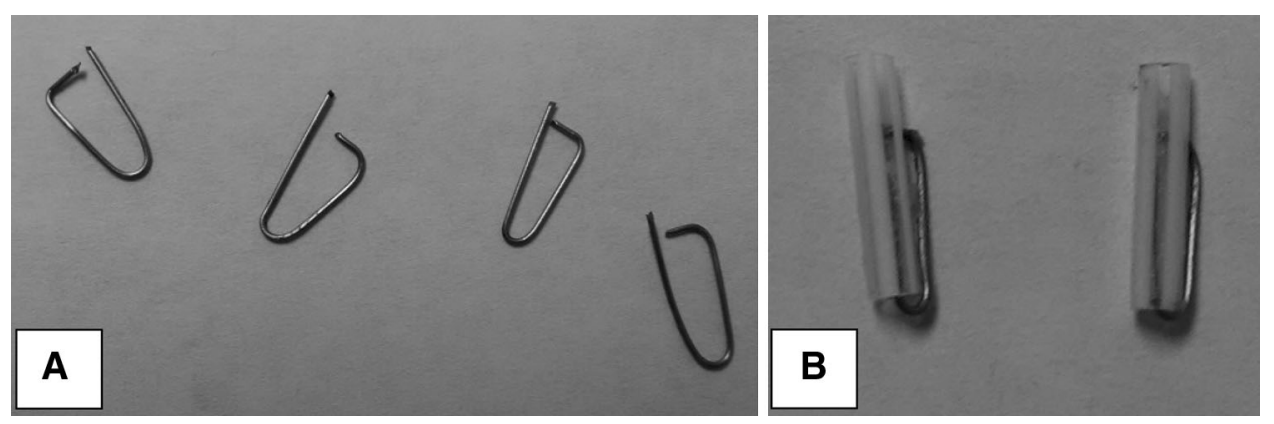

Fig. 2A-B Photographs represent (A) stainless steel wires bent into loop shapes before coating and insertion into catheters; and (B) after insertion of stainless steel wire into the catheter.
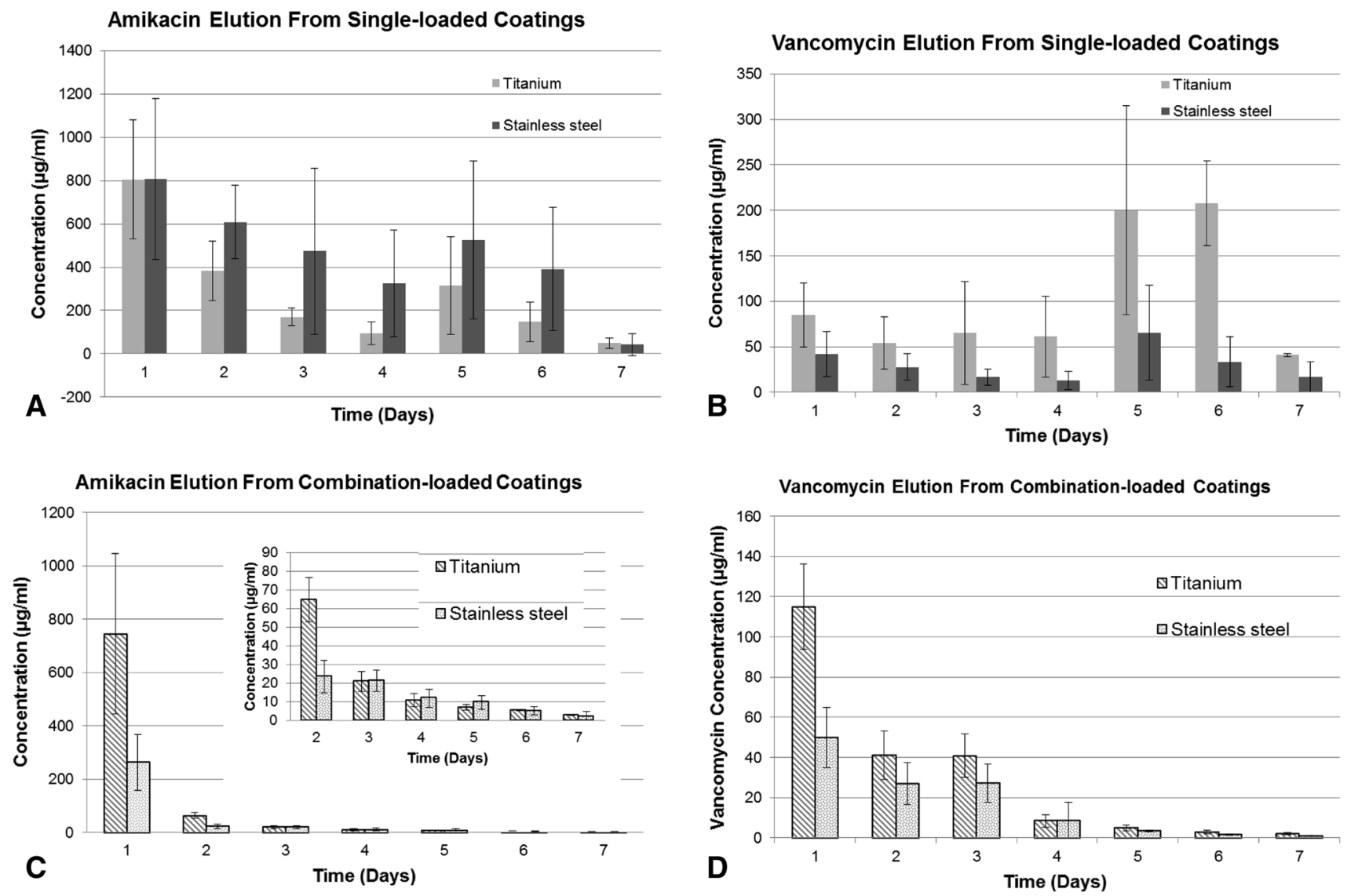

Fig. 3A-D Graphs show concentration of antibiotics in single-loaded coatings (A-B) and dual-loaded coatings $(\mathbf{C}-\mathbf{D})$ on titanium and stainless steel coupons in PBS eluates over 7 days of elution.

palladium $(20 \mathrm{~nm})$. Images at various locations on the coupons and at different magnifications were acquired using a Philips XL30 environmental scanning electron microscope (FEI, Hillsboro, OR, USA). Four coupons from each group were placed in $50-\mathrm{mL}$ centrifuge tubes in $10 \mathrm{~mL}$ of PBS and vortexed for approximately 1 minute to remove biofilm. The live bacteria removed were then serially diluted in 10-fold increments and plated for colony counting.
In Vivo Biofilm Inhibition

An established catheter biofilm model, using a subcutaneous dorsal implantation of a catheter segment [74], was modified to include a stainless steel wire (0.015-inch diameter, type $316 \mathrm{~L})$ that could be coated with antibiotic-loaded coating. To place the wire within the catheters without sharp edges exposed, the stainless steel wires were bent into loop shapes (Fig. 2A). Catheters had a hole punched $2 \mathrm{~mm}$ from one of 
the edges to insert the bent end of the wire (Fig. 2B). Wires and catheters were then washed, sterilized by autoclaving at $121^{\circ} \mathrm{C}$ for 20 minutes, and prepared for insertion into catheters by coating with designated coatings. The five coating-type groups (12 catheters in six mice) included uncoated wires; uncoated wires with codelivery of antibiotic solution $(1 \mu \mathrm{g} / \mathrm{mL}$ vancomycin; $16 \mu \mathrm{g} / \mathrm{mL}$ amikacin); phosphatidylcholine-only coated; AV-combination coated; and A-coated. Amikacin was chosen as a single high-dose antibiotic because of its activity against $S$ aureus as well as Gram-negative bacteria [58]. Two catheters from the same experimental group were implanted into the dorsa of each mouse bilaterally, one each on the right and left side of the spine, and then inoculated with a polymicrobial mixture of $10^{5}$ CFUs of $S$ aureus (UAMS- 1 ) and $10^{4}$ CFUs of $P$ aeruginosa (Schroeter) Migula (ATCC ${ }^{\circledR} 27317^{\mathrm{TM}}$, Manassas, VA, USA) directly into the lumen of the catheter. After 48 hours, catheters and wires were retrieved, rinsed, and separated for analysis of attached CFUs (10 catheters in five mice/group) and scanning electron microscopy imaging (two catheters in one mouse/group). Clearance rate was calculated by determining the number of catheters with $\mathrm{CFU}$ counts of zero and dividing by total number of catheters in that experimental group.

\section{Statistical Analysis}

Four replicates in each group were chosen for the elution and turbidity study based on activity and elution data from previous studies of calcium sulfate and chitosan-based drug delivery systems $[8,50]$ Based on a power analysis using SigmaPlot (Systat Software, Inc, San Jose, CA, USA), it was determined that a number of 4 provides approximately $80 \%$ power to detect a difference in proportions of solutions with complete growth inhibition of $84 \%$ at a significance level of $5 \%$ and provides over $80 \%$ power to detect differences in concentration of $15 \mu \mathrm{g} / \mathrm{mL}$ or more in antibiotic concentration given the standard deviation of approximately $5 \mu \mathrm{g} / \mathrm{mL}$. Three coupons in each group for the zone of inhibition study gives over $80 \%$ power to detect differences in clearing zones of $3 \mathrm{~mm}$ or more given the approximate SD of $0.9 \mathrm{~mm}$. For biofilm experiments, assuming a SD of approximately 0.36 , four coupons per group gives over $80 \%$ power to detect log-fold reductions in CFUs over 1 at a 5\% significance level. One-way Kruskal-Wallis analysis of variance with Student-Newman-Keuls test post hoc were performed using Sigma Plot (Systat Software, Inc, San Jose, CA, USA) to determine whether colony counts in coated coupons or wires differed from those in control groups. Using results of previous studies determining log-fold reduction of CFUs in response to antimicrobials [74], an a priori power analysis was performed using SigmaPlot. Assuming a SD of 1 unit in log-transformed CFU counts, five animals per group were required for $80 \%$ power to detect a difference of 3 units between the control group and each of the four experimental treatment groups at a significance level of $5 \%$.

\section{Results}

\section{In Vitro Elution}

For single loaded $25 \%$ antibiotic coatings, there was an initial burst of $800 \pm 371 \mu \mathrm{g} / \mathrm{mL}$ of amikacin or $84 \pm 34 \mu \mathrm{g} / \mathrm{mL}$ of vancomycin during the first day with decreasing elution until Days 5 and 6 when a second burst of antibiotic was present in both antibiotic groups (Fig. 3 A-B). Similar first day elution values of $746 \pm 300 \mu \mathrm{g} / \mathrm{mL}$ of amikacin and $115 \pm 21 \mu \mathrm{g} / \mathrm{mL}$ of vancomycin were observed for coatings loaded with $12.5 \%$ of both antibiotics (Fig. 3C-D). However, at the lower dual loading level, the burst at 5 days seen in $25 \%$ loaded coatings was not observed, and elution tapered off to below the minimum inhibitory concentration by approximately Day 5 .

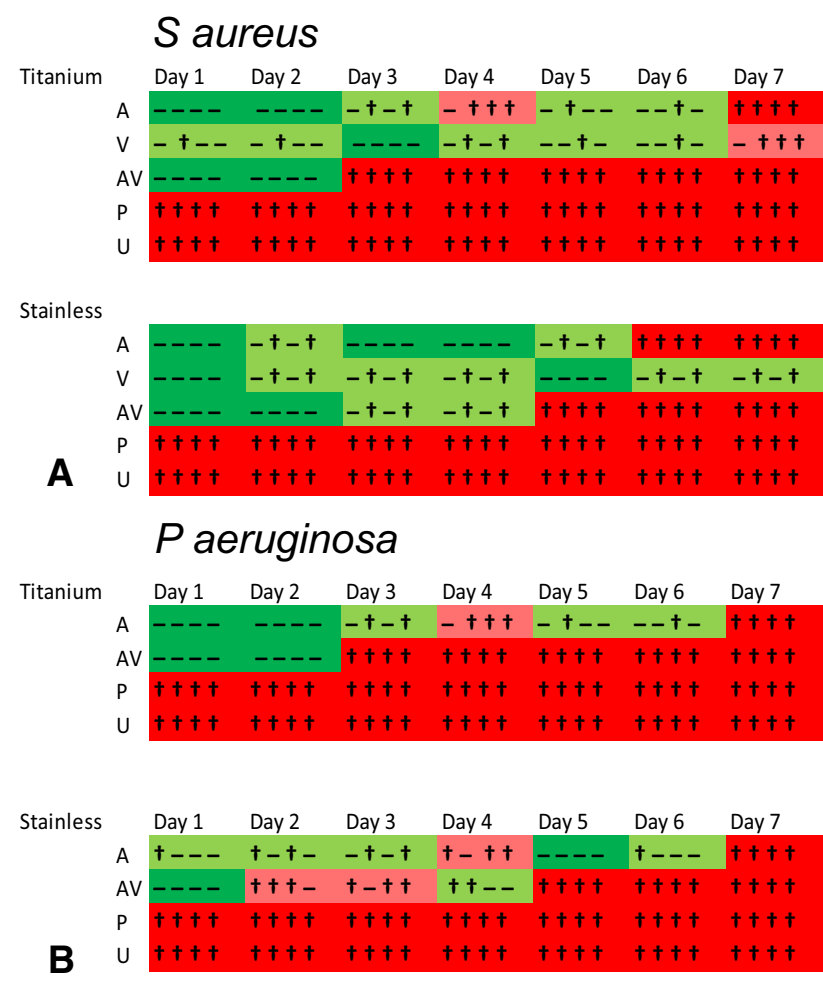

Fig. 4A-B Color-coded chart shows turbidity results for (A) $S$ aureus and (B) $P$ aeruginosa over a 7-day period for amikacin $25 \%$ (A); vancomycin $25 \%(\mathrm{~V})$; combination amikacin and vancomycin, $12.5 \%$ each (AV); phosphatidylcholine only (P); and uncoated controls (U). $\dagger \dagger \dagger \dagger=$ no growth inhibition; $-\dagger \dagger \dagger=$ growth inhibition in one sample; $-\dagger-\dagger=$ growth inhibition in multiple samples; - - - = growth inhibition in all samples. 


\section{In Vitro Colony Inhibition}

For $S$ aureus, $25 \%$ amikacin-loaded and $25 \%$ vancomycinloaded coatings had inhibitory effects for up to up to 3 days and also on Days 5 and 6 (Fig. 4A). Combination-loaded coatings with $12.5 \%$ of each antibiotic only inhibited growth of $S$ aureus for 2 days of elution. For $P$ aeruginosa, amikacin had inhibitory effects for up to 2 days of elution with increased inhibitory effects on Days 5 and 6 (Fig. 4B). Uncoated metal coupons had no effect on inhibition of bacterial growth and phosphatidylcholine released into the media without antibiotics also had no effect on bacterial turbidity. The combination coating with amikacin reduced to $12.5 \%$ only released inhibitory concentrations for 2 days on both stainless steel and titanium coupons. Visual inspection of coatings on coupons immersed in aqueous solutions indicated that less coating was visible on stainless steel coupons than titanium, starting at the 24-hour time point. A minute amount of residual phosphatidylcholine coating could be observed on titanium coupons for up to 5 to 7 days.

The antibiotic-loaded coatings had clear zones of inhibition compared with $\mathrm{P}$ and $\mathrm{U}$ controls. Average diameter of the zone of inhibition of vancomycin-loaded coating against $S$ aureus was $6 \pm 1 \mathrm{~mm}$ (Fig. 5A) and average zone of inhibition of amikacin-loaded coating against $P$ aeruginosa was $13 \pm 2 \mathrm{~mm}$ (Fig. 5B). Results showed that over the 24-hour period, all coatings, including nonantibiotic-loaded phosphatidylcholine, inhibited biofilm formation by $P$ aeruginosa on both titanium and stainless

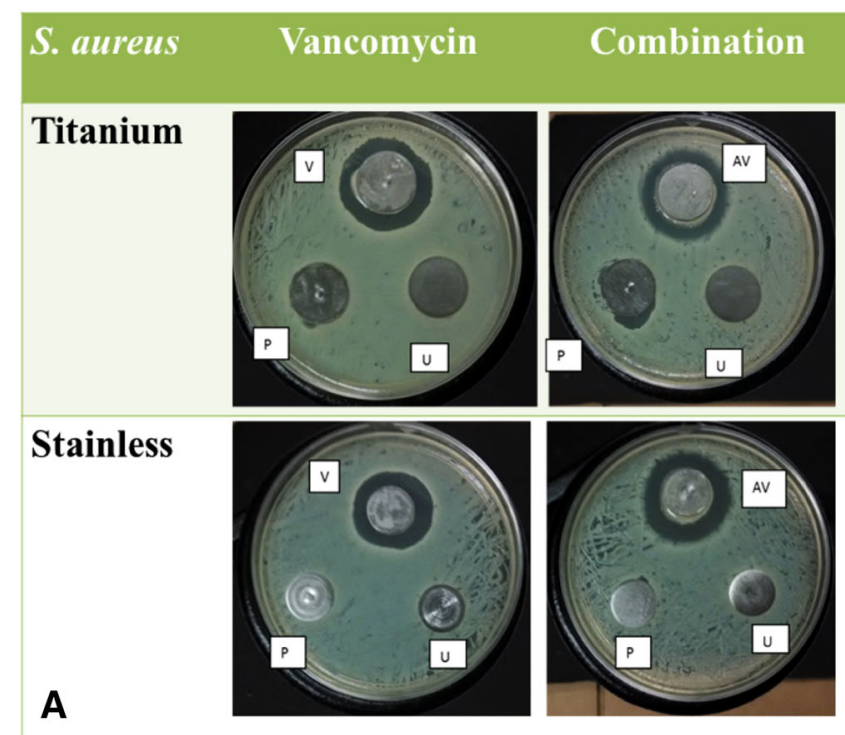

Fig. 5A-B Representative images show zone of inhibition results for (A) $S$ aureus and (B) $P$ aeruginosa using titanium (top two images) and stainless steel (bottom two images) coupons for vancomycin $25 \%$ steel coupons $(3.1 \pm 0 \log$-fold reduction, $95 \%$ confidence interval for the difference in means, -3.7 to -2.5 ; $\mathrm{p}<0.001)$. Although the phosphatidylcholine coating alone significantly reduced $S$ aureus biofilm formation on coupons $(4.3 \pm 0.4 \log$-fold reduction, $95 \%$ confidence interval for the difference in means, -5.1 to -3.6 ; $\mathrm{p}<0.001$ ), it did not completely inhibit attachment, and coated titanium seemed to have a decreased attachment compared with coated stainless steel (Fig. 6A). The antibiotic-loaded coatings resulted in a clearance rate of $100 \%$ in coupons inoculated with $P$ aeruginosa and a 56\% clearance rate in coupons inoculated with $S$ aureus. On titanium, there was a $3.1 \pm 0.0$ (95\% confidence interval for difference in means, -3.7 to $-2.5 ; \mathrm{p}<0.001) \log$-fold reduction of $P$ aeruginosa $\mathrm{CFUs/coupon}$ and a $5.6 \pm 0.2$ (95\% confidence interval for difference in means, -6.175 to $-4.827 ; \mathrm{p}<0.001) \log$-fold reduction of $S$ aureus on coupons coated with antibiotic-loaded phosphatidylcholine (Fig. 6). Images of biofilm formed on coupons demonstrated that control groups without coating had attached biofilm-forming bacterial colonies (Fig. 7), whereas few colonies were found in coated groups. Of note is that phosphatidylcholine and antibiotic-loaded phosphatidylcholine appeared to autofluoresce or bind to the dyes in the green channel at high lighting levels, especially when coated on titanium surfaces, giving an image of the surface characteristics of the coating. The coating appeared as "globules" of material with an occasional "spider web" appearance when combined with both amikacin and vancomycin. On titanium, coatings were observed to be

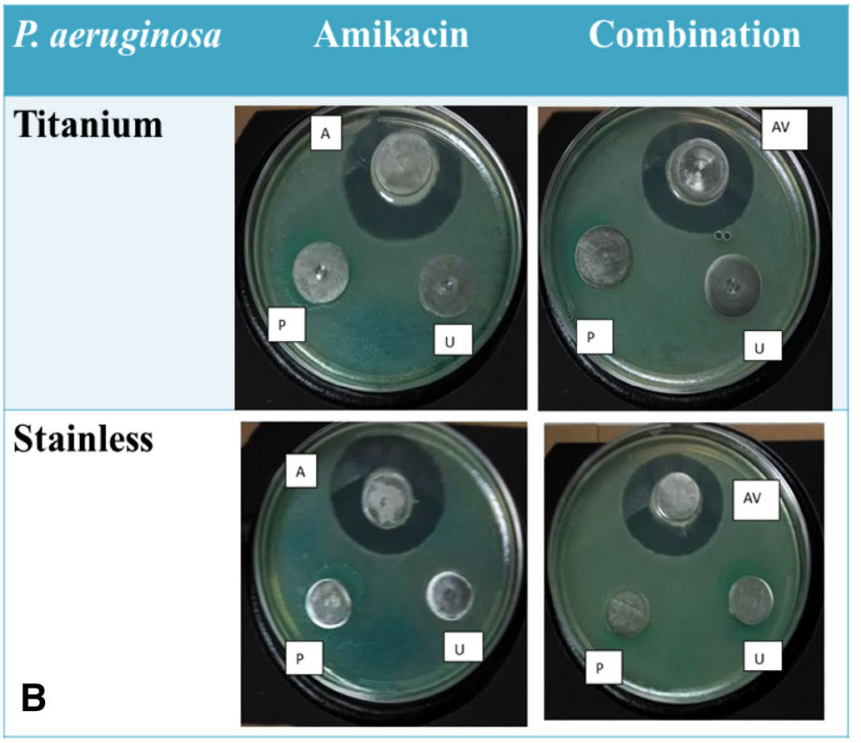

(V); combination amikacin and vancomycin, $12.5 \%$ each (AV); phosphatidylcholine only $(\mathrm{P})$; and uncoated controls (U). 


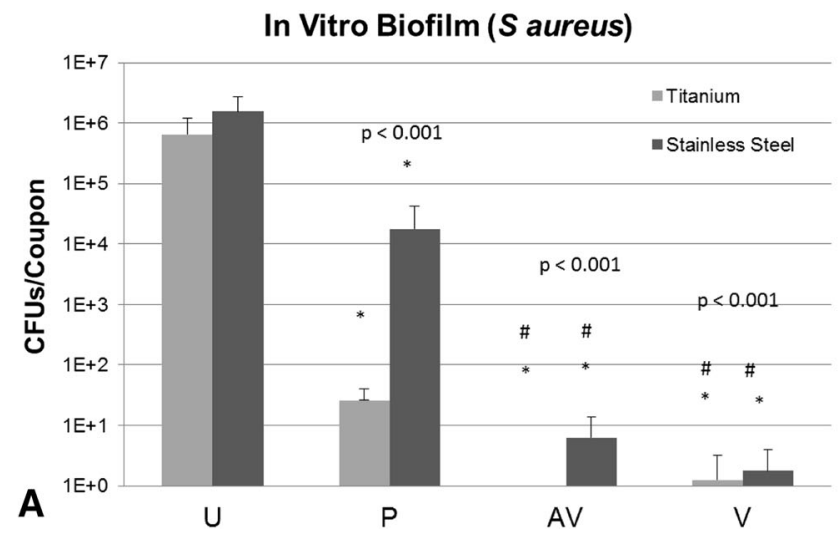

Fig. 6A-B Graph shows CFU counts from control and coated titanium and stainless steel coupons $(\mathrm{N}=4$ each) for (A) $S$ aureus and (B) $P$ aeruginosa. Data represented are mean \pm SD. Asterisks

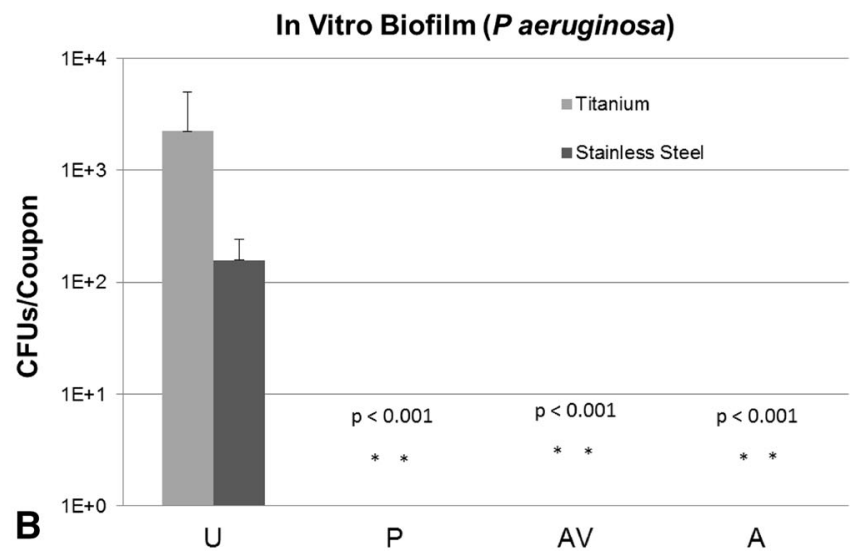

represent significant reduction in CFUs compared with the uncoated control; \# represents significant reduction in CFUs compared with the $\mathrm{P}$ control $(\mathrm{p}<0.001)$.

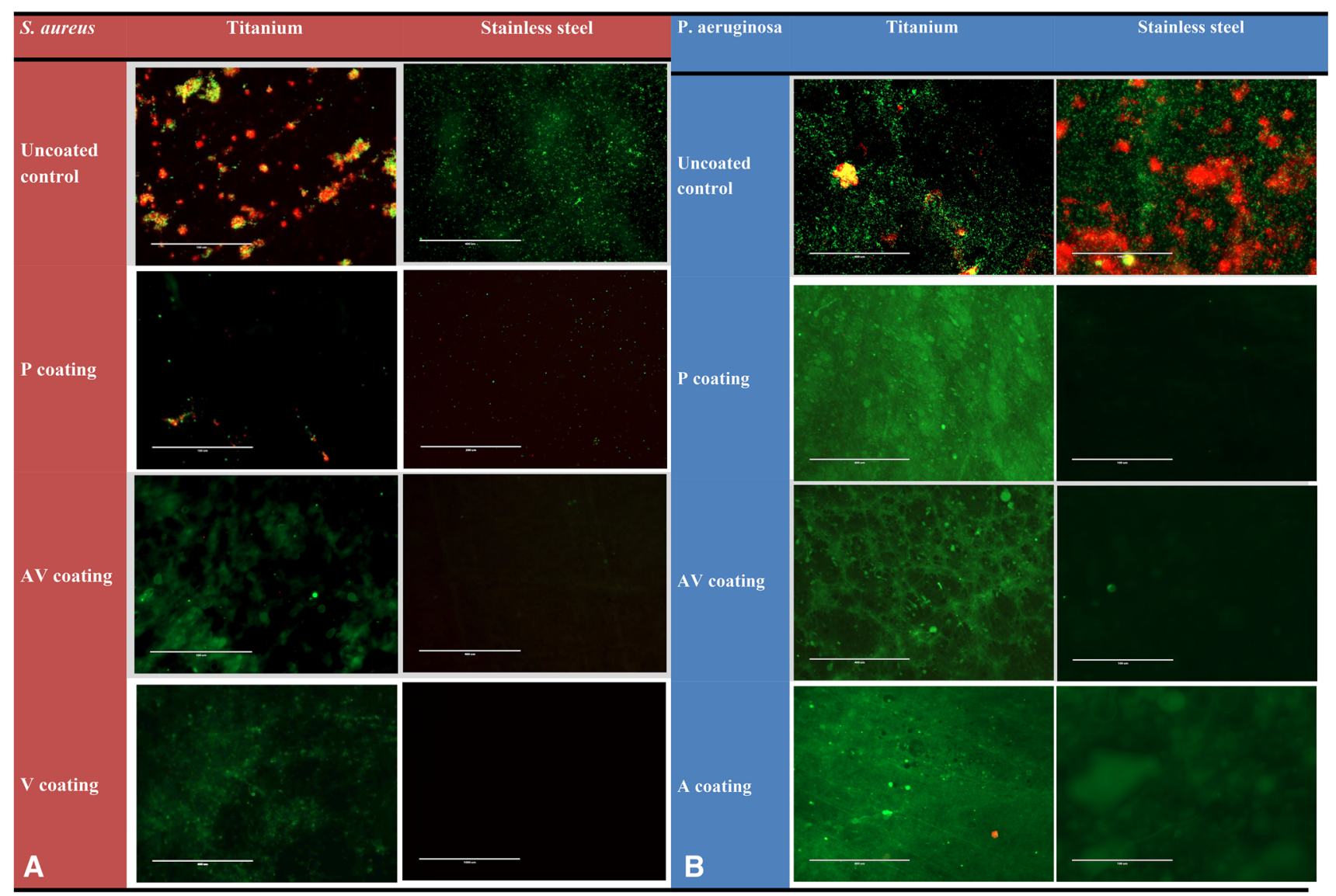

Fig. 7A-B Photomicrographs show (A) UAMS-1 and (B) PA01. Live bacteria appear green; dead bacteria appear red. Phosphatidylcholine coatings also demonstrate some autofluorescence in the green channel.

globular; coatings were sparse or absent on stainless steel coupons (Fig. 8). Some $S$ aureus bacteria were observed in phosphatidylcholine-only-coated coupons in both groups, confirming results of colony-counting studies.
In Vivo Inhibition and Clearance

Antibiotic-loaded coatings, both A alone and AV combination, were effective at inhibiting biofilm in vivo. 


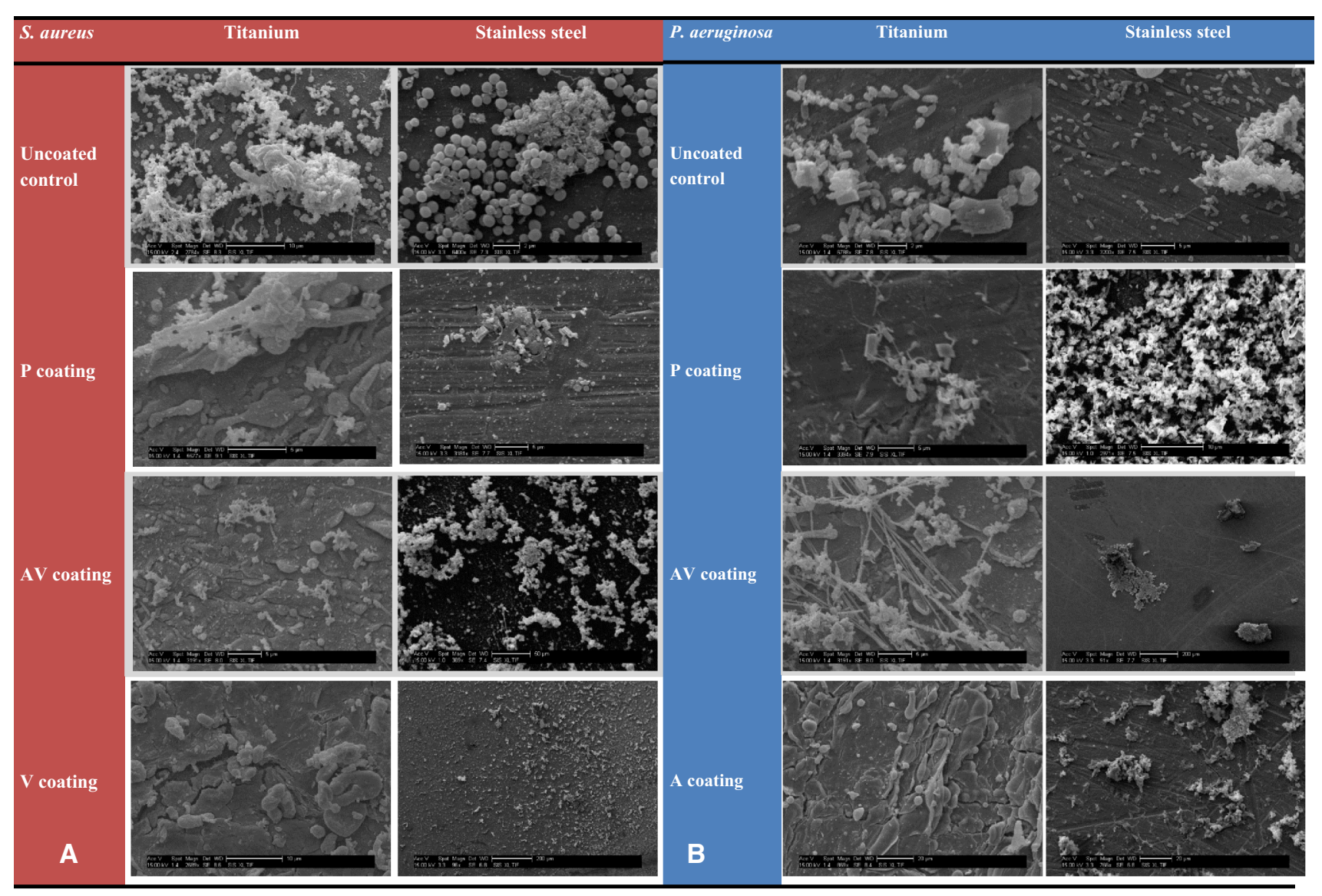

Fig. 8A-B Scanning electron micrographs show images at various magnifications of control and coated coupons inoculated with (A) UAMS-1. (B) PA01.
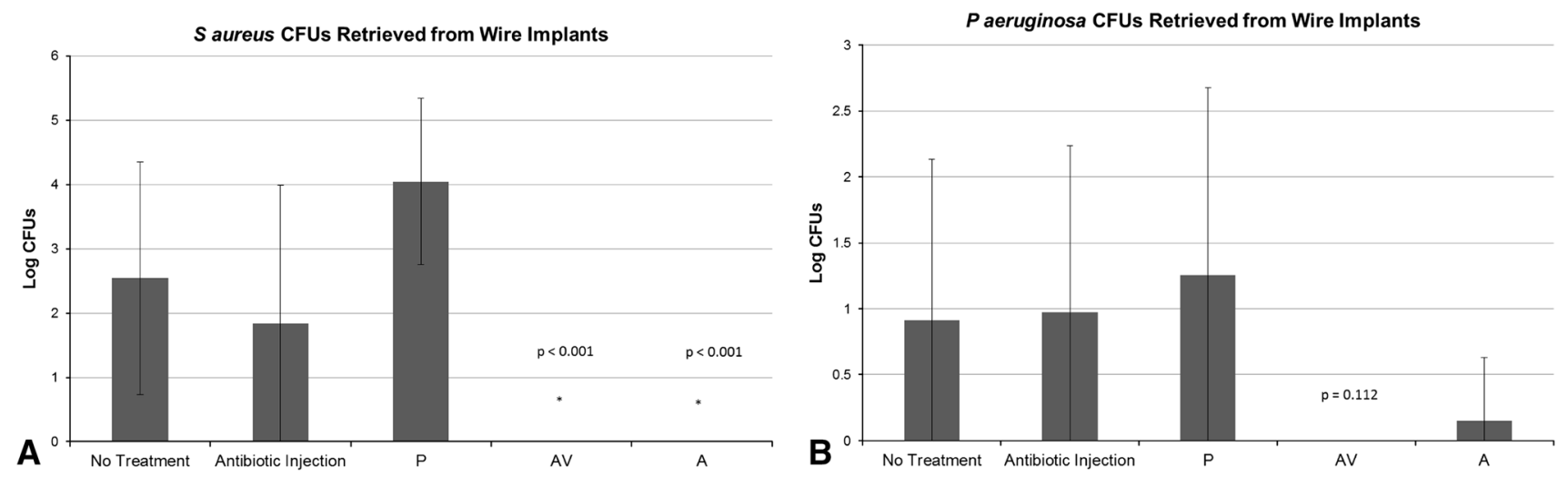

Fig. 9A-B Graph shows log CFU counts of (A) $S$ aureus and (B) $P$ aeruginosa from wire implants retrieved from in vivo study. Data represented are mean $\pm \mathrm{SD}$. Asterisks represent significant reduction in CFUs compared with the uncoated no treatment control.

Antibiotic-loaded coatings resulted in a $100 \%$ clearance rate of wires from $S$ aureus and a $90 \%$ clearance rate of $P$ aeruginosa in the polymicrobial in vivo model with one breakthrough in one wire in the in vivo study (Fig. 9). There was an average $2.5 \pm 0$ (95\% confidence interval for the difference in means, $1.342-3.743 ; \mathrm{p}<0.001) \log$-fold reduction of $S$ aureus biofilm formation on wires and a
$0.83 \pm 0.3(95 \%$ confidence interval for the difference in means, -0.1 to $1.6 ; \mathrm{p}=0.112) \log$-fold reduction of $P$ aeruginosa for antibiotic-loaded coatings compared with untreated controls. The $95 \%$ confidence interval for the difference in proportion of clearance of $S$ aureus was -1.407 to $-0.193(\mathrm{p}=0.053)$ and the simultaneous injection of antibiotics resulted in slightly higher clearance 


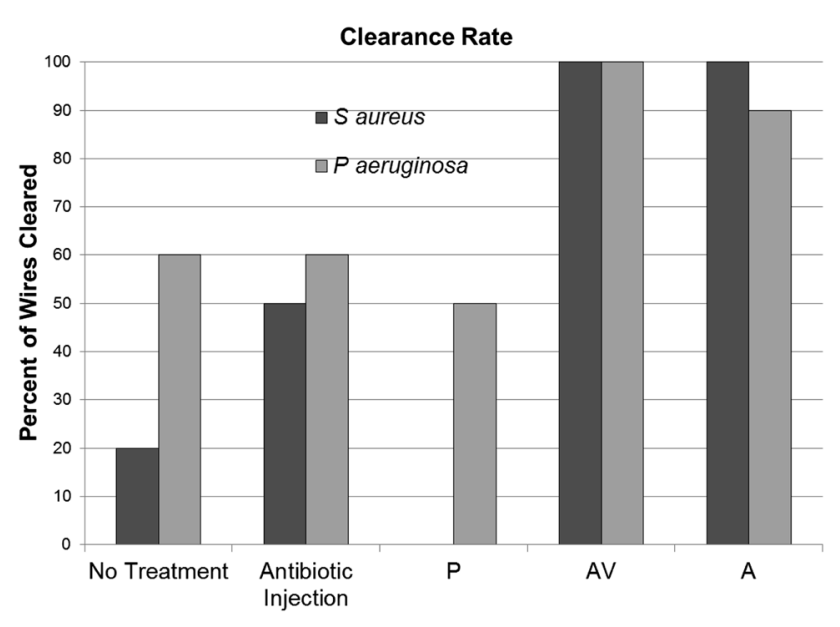

Fig. 10 Graph shows rate of clearance of implants from bacterial attachment calculated by dividing number of catheters completely clear of bacteria/number of implants (10 in each group).

rates of $S$ aureus than no treatment $(95 \%$ confidence interval for difference in proportions, -0.891 to 0.291 ; $\mathrm{p}=0.74$ ) (Fig. 10). There were no differences in clearance rates of $P$ aeruginosa. Wires with nonantibiotic coatings had no inhibitory effect on biofilm formation. Scanning electron microscopy images showed biofilm formation on uncoated wires but no observable bacterial colonies on wires coated with antibiotic-loaded phosphatidylcholine (Fig. 11).

\section{Discussion}

The treatment of extremity trauma can be complicated by polymicrobial infections and systemic antibiotic treatment that can be toxic to organ systems $[6,11,13,35,56,58]$. Localized antimicrobial drug delivery systems, including biomaterial carrier matrices and coatings on implants, have become a focus to combat biofilm formation and infection for both preventive and treatment strategies $[1,7,13,27$, $29,43,49,63,64]$. We provide the initial description of a novel lipid-based material we have developed to serve as a carrier matrix for antibiotics that can be applied to an implant with clinician-selected antibiotics at the point of care. In our preliminary study, we demonstrated that active antibiotics are eluted from coatings and showed antibiofilm efficacy in both in vitro and in vivo models.

Our results should be interpreted in light of the limitations of our study. The in vitro tests were preliminary measures designed to estimate preliminary elution, retention, and antimicrobial properties of coatings. The elution and turbidity studies do not fully replicate conditions within an orthopaedic defect; however, the tests have previously been used with various drug delivery systems to characterize elution patterns and confirm antibiotic activity [41, 57, 73]. "Rinsing" or "dipping" metal implants in antibiotic has shown some biofilm inhibitory properties [19, 31, 59], although we did not include control groups with coupons soaked in antibiotics for in vitro tests because antibiotic coatings applied in this manner and not chemically bonded to the implants have been shown to release over $90 \%$ of antibiotic within 6 hours and are less effective in vivo than prefabricated coatings $[19,37]$. We did, however, have an experimental group in the in vivo study with coadministration of antibiotics to uncoated wires, which is similar to this type of implant treatment. Among types of sampling, complete refreshment of media with daily time points has been shown to influence the elution profile of antibiotic from the drug delivery vehicle, calcium sulfate [41], and this sampling method was chosen as a "worst case" scenario. The elution of antibiotic from phosphatidylcholine coatings within an orthopaedic defect may be extended compared with the calcium sulfate elution profile. We did not characterize the roughness of the metal coupons because they were sanded to a uniform finish for our study. Actual implant surface irregularities or varying degrees of roughness may influence the retention of coatings and affect elution profile [20,61]. A further limitation is that although we measured elution of drug from the matrix, we did not quantify persistence, degradation, or release of phosphatidylcholine coating into elution media in this study. However, we did visually observe coatings on coupons and noted that undissolved phosphatidylcholine was present in saline elution media and that visible pieces of solid phosphatidylcholine were present on coupons up to Day 7.

The biofilm formation on each type of coupon appeared to be consistent with other studies of biofilm [33, 38]. Although other model systems are available for in vitro biofilm evaluation, including biofilm reactor systems with shear flow components that may simulate physiologic conditions $[12,18]$, we chose a static culture model to address antibiofilm activity initially. Although there may be differences in elution of antibiotics and bacterial adhesion under shear flow conditions, we believe that the static model provides a useful initial simulation of the conditions of orthopaedic defects with limited vascularity. Future studies may address the effects of fluid shear and constant media perfusion on elution and activity characteristics. The limitations of the animal model include the small size, soft tissue instead of orthopaedic implantation, and limited diffusion of physiologic substances within the sequestrum of the catheter. The animal model is useful as a screening tool for antibiofilm activity in vivo [54, 74, 75], where the catheter serves as a sequestrum for localizing the bacterial inoculum and as a nidus for biofilm formation. Because of difficulty in applying coatings directly to the catheter, we 

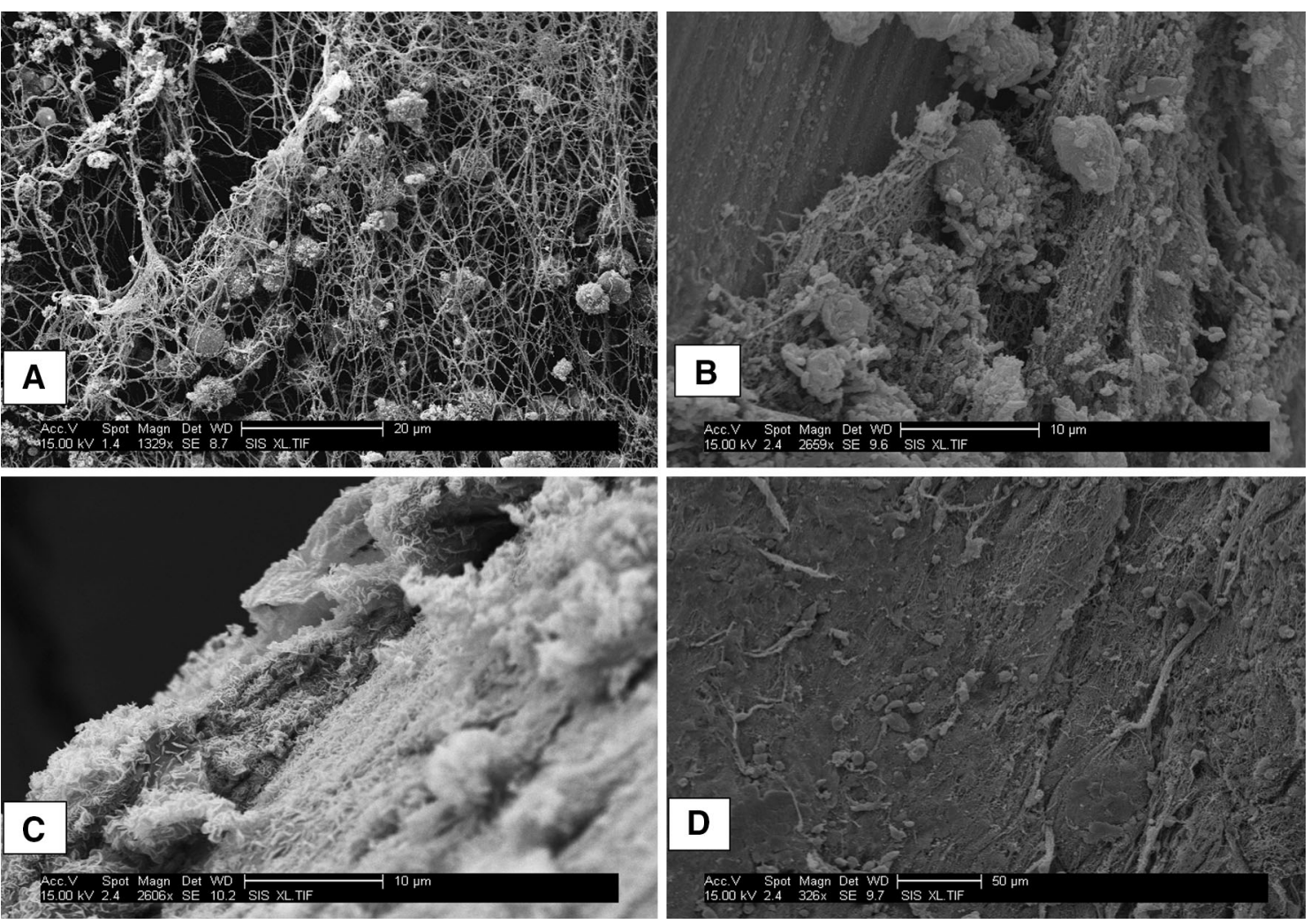

Fig. 11A-D Scanning electron micrographs show surfaces of wires from inner portion of catheter wire in untreated control group (A-B) and antibiotic-loaded phosphatidylcholine-coated wires $(\mathbf{C}-\mathbf{D})$.

modified the catheter-associated biofilm model by including an easily coated stainless steel wire. Minimal diffusion of fluid within the lumen of the catheter is a limitation of this model in modeling physiological conditions to test local drug delivery devices and the modification of this model to include wires has not been previously validated. Part of the wire was within the catheter lumen, and the other part was exposed to the soft tissue and shear forces resulting from fluid flow and animal movement. Despite the limitations, our model provided a proof of principle that the coatings inhibited biofilm formation on the wires. Diffusion and elution were not characterized over a 48hour time course, but reduction in bacterial attachment confirmed release of active antibiotics observed in our in vitro studies. Future evaluations using coatings on orthopaedic implants in more complex models should follow our studies to confirm efficacy in clinically relevant orthopaedic applications [8, 10, 62].

Elution of antibiotics from phosphatidylcholine coatings applied to metal surfaces is initially described to follow a burst release pattern with a second burst of antibiotic after Day 5 when loaded at high concentration. We propose that some of the crystals of antibiotic are entrapped within lipid chains of phosphatidylcholine and that others are not bound within lipid chains. Initial release of unbound antibiotic is similar for different loading levels. Antibiotics not released during this initial period may be released as the phosphatidylcholine molecules degrade or are hydrolyzed resulting in the second burst effect. Amikacin, a smaller molecule (molecular weight $585 \mathrm{~g} / \mathrm{mol}$ ) than vancomycin (molecular weight $1449 \mathrm{~g} / \mathrm{mol}$ ), was released at a much higher level during the first day of elution. Differences in molecular weight and chemical structure may affect retention and release of different antibiotics from phosphatidylcholine. Antibiotics released from coatings were confirmed to be active in inhibiting growth of microorganisms through turbidity and zone of inhibition assays with similar activity to other antimicrobial coatings [5, 14, 25, 43, 69]. Although effective in inhibiting bacterial growth and biofilm formation, several of the implant coating strategies have the limitation of requiring prefabrication $[25,43]$ and chemical modification with specific preselected antibiotics [4, 29]. Release of antibiotic resembles the burst release observed in commonly used polymethylmethacrylate (PMMA) and calcium sulfate drug delivery matrices [23, 47]. Unlike PMMA, which requires secondary removal through surgical procedures, phosphatidylcholine coatings are degradable and materials have been used in orthopaedic applications [26]. Through application to the surface directly, more coverage of the potentially contaminated 
implant site is provided compared with antibiotic-loaded beads or sponges [34, 67, 70, 76].

Interestingly, we observed some inhibitory effect of unloaded phosphatidylcholine on biofilm formation in vitro, which may be a result of the hydrophobic nature of the coating [21]. P aeruginosa biofilm was completely inhibited by coatings in the 24-hour in vitro biofilm assay, which is similar to the response of Gram-negative organisms to hydrophobic surfaces in a study by Cheng et al. [17]. The inhibitory effect of coating without antibiotic was not observed in the in vivo study, likely as a result of the competing effects of protein and cell adhesion $[3,78,79]$. Novel nanoparticle systems releasing antibiotics or antimicrobial silver have been shown to similarly inhibit bacterial growth and biofilm formation, but balancing bactericidal efficacy against cytotoxicity to the surrounding cells must be a consideration before clinical use $[2,7,16,39]$.

The reduction in biofilm attachment in a challenging polymicrobial in vivo model confirms the in vitro results and is consistent with release of active concentrations of antibiotic from various drug delivery vehicles $[22,45,51$, 54, 63]. Scanning electron microscopy images of biofilm formation on implants resembled images from similar retrieved infected implants $[10,52]$ with rounded $S$ aureus and rod-shaped $P$ aeruginosa colonies visible in untreated groups. Formation of fibrous tissue, to varying degrees, along the outer portion of the wire exposed to soft tissue was seen with morphology that may be indicative of fibroblast or macrophage infiltration $[3,23,36]$. Material properties of the coating may have contributed to this response [26, 77]; however, the majority of the fibrous tissue was formed at the point of the wire that curved and extended from the catheter, which may have been a location for rubbing and irritation as the animals moved or were groomed.

In conclusion, phosphatidylcholine coatings are capable of local delivery of active antibiotics and can be loaded with antimicrobials to inhibit biofilm. Reduction of biofilm on metal may be the result of a combination of lipid material properties and localized antibiotic release. Antibiotic-loaded phosphatidylcholine coatings reduced bacterial growth and biofilm formation on coated metal substrates. We plan further development and testing, including investigating efficacy in orthopaedic models and use of different antimicrobial-loading strategies.

\section{References}

1. Adams CS, Antoci V Jr, Harrison G, Patal P, Freeman TA, Shapiro IM, Parvizi J, Hickok NJ, Radin S, Ducheyne P. Controlled release of vancomycin from thin sol-gel films on implant surfaces successfully controls osteomyelitis. J Orthop Res. 2009;27:701-709.
2. Albers CE, Hofstetter W, Siebenrock KA, Landmann R, Klenke FM. In vitro cytotoxicity of silver nanoparticles on osteoblasts and osteoclasts at antibacterial concentrations. Nanotoxicology. 2013;7:30-36.

3. Anderson JM, Rodriguez A, Chang DT. Foreign body reaction to biomaterials. Semin Immunol. 2008;20:86-100.

4. Antoci V Jr, Adams CS, Hickok NJ, Shapiro IM, Parvizi J. Vancomycin bound to Ti rods reduces periprosthetic infection: preliminary study. Clin Orthop Relat Res. 2007;461:88-95.

5. Antoci V Jr, King SB, Jose B, Parvizi J, Zeiger AR, Wickstrom E, Freeman TA, Composto RJ, Ducheyne P, Shapiro IM, Hickok NJ, Adams CS. Vancomycin covalently bonded to titanium alloy prevents bacterial colonization. J Orthop Res. 2007;25:858-866.

6. Bailie GR, Neal D. Vancomycin ototoxicity and nephrotoxicity. A review. Med Toxicol Adverse Drug Exp. 1988;3:376-386.

7. Barbour ME, Maddocks SE, Wood NJ, Collins AM. Synthesis, characterization, and efficacy of antimicrobial chlorhexidine hexametaphosphate nanoparticles for applications in biomedical materials and consumer products. Int J Nanomedicine. 2013;8:3507-3519.

8. Beenken K, Smith J, Skinner R, MClaren S, Bellamy W, Gruenwald M, Spencer HJ, Jennings J, Haggard W, Smeltzer M. Chitosan coating to enhance the therapeutic efficacy of calcium sulfate-based antibiotic therapy in the treatment of chronic osteomyelitis. J Biomater Appl. 2014;29:514-523.

9. Beenken KE, Blevins JS, Smeltzer MS. Mutation of sarA in Staphylococcus aureus limits biofilm formation. Infect Immun. 2003;71:4206-4211.

10. Bernthal NM, Stavrakis AI, Billi F, Cho JS, Kremen TJ, Simon SI, Cheung AL, Finerman GA, Lieberman JR, Adams JS, Miller LS. A mouse model of post-arthroplasty Staphylococcus aureus joint infection to evaluate in vivo the efficacy of antimicrobial implant coatings. PLoS One. 2010;5:e12580.

11. Brady RA, Leid JG, Calhoun JH, Costerton JW, Shirtliff ME. Osteomyelitis and the role of biofilms in chronic infection. FEMS Immunol Med Microbiol. 2008;52:13-22.

12. Buckingham-Meyer K, Goeres DM, Hamilton MA. Comparative evaluation of biofilm disinfectant efficacy tests. $J$ Microbiol Meth. 2007;70:236-244.

13. Campoccia D, Montanaro L, Arciola CR. The significance of infection related to orthopedic devices and issues of antibiotic resistance. Biomaterials. 2006;27:2331-2339.

14. Campoccia D, Montanaro L, Arciola CR. A review of the biomaterials technologies for infection-resistant surfaces. Biomaterials. 2013;34:8533-8554.

15. Campoccia D, Montanaro L, Arciola CR. A review of the clinical implications of anti-infective biomaterials and infection-resistant surfaces. Biomaterials. 2013;34:8018-8029.

16. Chavez de Paz LE, Resin A, Howard KA, Sutherland DS, Wejse PL. Antimicrobial effect of chitosan nanoparticles on streptococcus mutans biofilms. Appl Environ Microbiol. 2011;77:3892-3895.

17. Cheng G, Zhang Z, Chen S, Bryers JD, Jiang S. Inhibition of bacterial adhesion and biofilm formation on zwitterionic surfaces. Biomaterials. 2007;28:4192-4199.

18. Coenye T, Nelis HJ. In vitro and in vivo model systems to study microbial biofilm formation. J Microbiol Meth. 2010;83:89-105.

19. Darouiche RO, Mansouri MD, Zakarevicz D, Alsharif A, Landon GC. In vivo efficacy of antimicrobial-coated devices. J Bone Joint Surg Am. 2007;89:792-797.

20. Dearnley PA. A review of metallic, ceramic and surface-treated metals used for bearing surfaces in human joint replacements. Proc Inst Mech Eng H. 1999;213:107-135.

21. Donlan RM. Biofilms: microbial life on surfaces. Emerg Infect Dis. 2002;8:881-890.

22. Doty HA, Leedy MR, Courtney HS, Haggard WO, Bumgardner JD. Composite chitosan and calcium sulfate scaffold for dual 
delivery of vancomycin and recombinant human bone morphogenetic protein-2. J Mater Sci Mater Med. 2014;25:1449-1459.

23. Gerhart TN, Roux RD, Horowitz G, Miller RL, Hanff P, Hayes WC. Antibiotic release from an experimental biodegradable bone cement. J Orthop Res. 1988;6:585-592.

24. Giavaresi G, Bertazzoni Minelli E, Sartori M, Benini A, Della Bora T, Sambri V, Gaibani P, Borsari V, Salamanna F, Martini L, Nicoli Aldini N, Fini M. Microbiological and pharmacological tests on new antibiotic-loaded PMMA-based composites for the treatment of osteomyelitis. J Orthop Res. 2012;30:348-355.

25. Greene AH, Bumgardner JD, Yang Y, Moseley J, Haggard WO. Chitosan-coated stainless steel screws for fixation in contaminated fractures. Clin Orthop Relat Res. 2008;466:1699-1704.

26. Han B, Tang B, Nimni ME. Combined effects of phosphatidylcholine and demineralized bone matrix on bone induction. Connect Tissue Res. 2003;44:160-166.

27. Jennings JA, Courtney HS, Haggard WO. Cis-2-decenoic acid inhibits S. aureus growth and biofilm in vitro: a pilot study. Clin Orthop Relat Res. 2012;470:2663-2670.

28. Kapadia BH, Pivec R, Johnson AJ, Issa K, Naziri Q, Daley JA, Mont MA. Infection prevention methodologies for lower extremity total joint arthroplasty. Expert Rev Med Devic. 2013;10:215-224.

29. Ketonis C, Barr S, Adams CS, Shapiro IM, Parvizi J, Hickok NJ. Vancomycin bonded to bone grafts prevents bacterial colonization. Antimicrob Agents Chemother. 2011;55:487-494.

30. Ketonis C, Parvizi J, Jones LC. Evolving strategies to prevent implant-associated infections. $J$ Am Acad Orthop Surg. 2012;20:478-480.

31. Koban I, Holtfreter B, Hubner NO, Matthes R, Sietmann R, Kindel E, Weltmann KD, Welk A, Kramer A, Kocher T. Antimicrobial efficacy of non-thermal plasma in comparison to chlorhexidine against dental biofilms on titanium discs in vitro - proof of principle experiment. J Clin Periodontol. 2011;38:956-965.

32. Kuo J. Electron Microscopy: Methods and Protocols. Totowa, NJ, USA: Humana Press; 2007.

33. Lauderdale KJ, Malone CL, Boles BR, Morcuende J, Horswill AR. Biofilm dispersal of community-associated methicillinresistant Staphylococcus aureus on orthopedic implant material. $J$ Orthop Res. 2010;28:55-61.

34. Lewis G, Brooks JL, Courtney HS, Li Y, Haggard WO. An approach for determining antibiotic loading for a physiciandirected antibiotic-loaded PMMA bone cement formulation. Clin Orthop Relat Res. 2010;468:2092-2100.

35. Logan TB, Prazma J, Thomas WG, Fischer ND. Tobramycin ototoxicity. Arch Otolaryngol. 1974;99:190-193.

36. Lv W, Luo J, Deng Y, Sun Y. Biomaterials immobilized with chitosan for rechargeable antimicrobial drug delivery. J Biomed Mater Res A. 2013;101:447-455.

37. Mansouri MD, Boone TB, Darouiche RO. Comparative assessment of antimicrobial activities of antibiotic-treated penile prostheses. Eur Urol. 2009;56:1039-1045.

38. Marques SC, Rezende JDOS, Alves LAD, Silva BC, Alves E, de Abreu LR, Piccoli RH. Formation of biofilms by Staphylococcus aureus on stainless steel and glass surfaces and its resistance to some selected chemical sanitizers. Braz J Microbiol. 2007;38:538-543.

39. Mathew TV, Kuriakose S. Photochemical and antimicrobial properties of silver nanoparticle-encapsulated chitosan functionalized with photoactive groups. Mater Sci Eng C Mater Biol Appl. 2013;33:4409-4415.

40. McConoughey SJ, Howlin RP, Wiseman J, Stoodley P, Calhoun JH. Comparing PMMA and calcium sulfate as carriers for the local delivery of antibiotics to infected surgical sites. J Biomed Mater Res B Appl Biomater. 2014 Aug 20 [Epub ahead of print].

41. McLaren AC, McLaren SG, Nelson CL, Wassell DL, Olsen KM. The effect of sampling method on the elution of tobramycin from calcium sulfate. Clin Orthop Relat Res. 2002;403:54-57.
42. Molinari RW, Khera OA, Molinari WJ, 3rd. Prophylactic intraoperative powdered vancomycin and postoperative deep spinal wound infection: 1,512 consecutive surgical cases over a 6-year period. Eur Spine J. 2012;21(Suppl 4):S476-482.

43. Norowski PA, Courtney HS, Babu J, Haggard WO, Bumgardner JD. Chitosan coatings deliver antimicrobials from titanium implants: a preliminary study. Implant Dent. 2011;20:56-67.

44. Norowski PA Jr, Bumgardner JD. Biomaterial and antibiotic strategies for peri-implantitis: a review. J Biomed Mater Res B Appl Biomater. 2009;88:530-543.

45. Olson PD, Kuechenmeister LJ, Anderson KL, Daily S, Beenken KE, Roux CM, Reniere ML, Lewis TL, Weiss WJ, Pulse M, Nguyen P, Simecka JW, Morrison JM, Sayood K, Asojo OA, Smeltzer MS, Skaar EP, Dunman PM. Small molecule inhibitors of Staphylococcus aureus RnpA alter cellular mRNA turnover, exhibit antimicrobial activity, and attenuate pathogenesis. PLoS Pathog. 2011;7:e1001287.

46. Omar MA, Ahmed HM, Hammad MA, Derayea SM. Validated spectrofluorimetric method for determination of selected aminoglycosides. Spectrochim Acta A Mol Biomol Spectrosc. 2015;135:472-478.

47. Orellana BR, Hilt JZ, Puleo DA. Drug release from calcium sulfate-based composites. J Biomed Mater Res B Appl Biomater. 2015;103:135-142.

48. Overstreet D, McLaren A, Calara F, Vernon B, McLemore R. Local gentamicin delivery from resorbable viscous hydrogels is therapeutically effective. Clin Orthop Relat Res. 2014 Sep 17 [Epub ahead of print].

49. Overstreet DJ, Huynh R, Jarbo K, McLemore RY, Vernon BL. In situ forming, resorbable graft copolymer hydrogels providing controlled drug release. J Biomed Mater Res A. 2013;101:14371446.

50. Parker AC, Beenken KE, Jennings JA, Hittle L, Shirtliff ME, Bumgardner JD, Smeltzer MS, Haggard WO. Characterization of local delivery with amphotericin B and vancomycin from modified chitosan sponges and functional biofilm prevention evaluation. J Orthop Res. 2014 Nov 18 [Epub ahead of print].

51. Parker AC, Jennings JA, Bumgardner JD, Courtney HS, Lindner E, Haggard WO. Preliminary investigation of crosslinked chitosan sponges for tailorable drug delivery and infection control. $J$ Biomed Mater Res B Appl Biomater. 2013;101:110-123.

52. Pribaz JR, Bernthal NM, Billi F, Cho JS, Ramos RI, Guo Y, Cheung AL, Francis KP, Miller LS. Mouse model of chronic post-arthroplasty infection: noninvasive in vivo bioluminescence imaging to monitor bacterial burden for long-term study. $J$ Orthop Res. 2012;30:335-340.

53. Pritchard EM, Valentin T, Panilaitis B, Omenetto F, Kaplan DL. Antibiotic-releasing silk biomaterials for infection prevention and treatment. Adv Funct Mater. 2013;23:854-861.

54. Quave CL, Estevez-Carmona M, Compadre CM, Hobby G, Hendrickson H, Beenken KE, Smeltzer MS. Ellagic acid derivatives from Rubus ulmifolius inhibit Staphylococcus aureus biofilm formation and improve response to antibiotics. PLoS One. 2012;7:e28737.

55. Ranall MV, Butler MS, Blaskovich MA, Cooper MA. Resolving biofilm infections: current therapy and drug discovery strategies. Curr Drug Targets. 2012;13:1375-1385.

56. Rathbone CR, Cross JD, Brown KV, Murray CK, Wenke JC. Effect of various concentrations of antibiotics on osteogenic cell viability and activity. J Orthop Res. 2011;29:1070-1074.

57. Richelsoph KC, Webb ND, Haggard WO. Elution behavior of daptomycin-loaded calcium sulfate pellets: a preliminary study. Clin Orthop Relat Res. 2007;461:68-73.

58. Sabath LD, Garner C, Wilcox C, Finland M. Susceptibility of Staphylococcus aureus and Staphylococcus epidermidis to 65 antibiotics. Antimicrob Agents Chemother. 1976;9:962-969. 
59. Schwarz F, Sculean A, Romanos G, Herten M, Horn N, Scherbaum W, Becker J. Influence of different treatment approaches on the removal of early plaque biofilms and the viability of SAOS2 osteoblasts grown on titanium implants. Clin Oral Invest. 2005;9:111-117.

60. Shah SR, Tatara AM, D'Souza RN, Mikos AG, Kasper FK. Evolving strategies for preventing biofilm on implantable materials. Mater Today. 2013;16:177-182.

61. Shalabi MM, Gortemaker A, Van't Hof MA, Jansen JA, Creugers NH. Implant surface roughness and bone healing: a systematic review. J Dent Res. 2006;85:496-500.

62. Smeltzer MS, Thomas JR, Hickmon SG, Skinner RA, Nelson CL, Griffith D, Parr TR Jr, Evans RP. Characterization of a rabbit model of staphylococcal osteomyelitis. J Orthop Res. 1997;15:414-421.

63. Smith JK, Bumgardner JD, Courtney HS, Smeltzer MS, Haggard WO. Antibiotic-loaded chitosan film for infection prevention: a preliminary in vitro characterization. J Biomed Mater Res B Appl Biomater. 2010;94:203-211.

64. Smith JK, Moshref AR, Jennings JA, Courtney HS, Haggard WO. Chitosan sponges for local synergistic infection therapy: a pilot study. Clin Orthop Relat Res. 2013;471:3158-3164.

65. Stewart PS, Costerton JW. Antibiotic resistance of bacteria in biofilms. Lancet. 2001;358:135-138.

66. Stewart S, Barr S, Engiles J, Hickok NJ, Shapiro IM, Richardson DW, Parvizi J, Schaer TP. Vancomycin-modified implant surface inhibits biofilm formation and supports bone-healing in an infected osteotomy model in sheep: a proof-of-concept study. $J$ Bone Joint Surg Am. 2012;94:1406-1415.

67. Stinner DJ, Noel SP, Haggard WO, Watson JT, Wenke JC. Local antibiotic delivery using tailorable chitosan sponges: the future of infection control? J Orthop Trauma. 2010;24:592-597.

68. Stoodley P, Ehrlich GD, Sedghizadeh PP, Hall-Stoodley L, Baratz ME, Altman DT, Sotereanos NG, Costerton JW, Demeo P. Orthopaedic biofilm infections. Curr Orthop Pract. 2011;22:558-563.

69. Swanson TE, Cheng X, Friedrich C. Development of chitosanvancomycin antimicrobial coatings on titanium implants. $J$ Biomed Mater Res A. 2011;97:167-176.
70. Turner TM, Urban RM, Hall DJ, Chye PC, Segreti J, Gitelis S. Local and systemic levels of tobramycin delivered from calcium sulfate bone graft substitute pellets. Clin Orthop Relat Res. 2005;437:97-104.

71. Uckay I, Hoffmeyer P, Lew D, Pittet D. Prevention of surgical site infections in orthopaedic surgery and bone trauma: state-ofthe-art update. J Hosp Infect. 2013;84:5-12.

72. Vila MMDC, de Oliveira RM, Goncalves MM, Tubino M. Analytical methods for vancomycin determination in biological fluids and in pharmaceuticals. Quim Nova. 2007;30:395-399.

73. Weiss BD, Weiss EC, Haggard WO, Evans RP, McLaren SG, Smeltzer MS. Optimized elution of daptomycin from polymethylmethacrylate beads. Antimicrob Agents Chemother. 2009;53:264-266.

74. Weiss EC, Spencer HJ, Daily SJ, Weiss BD, Smeltzer MS. Impact of sarA on antibiotic susceptibility of Staphylococcus aureus in a catheter-associated in vitro model of biofilm formation. Antimicrob Agents Chemother. 2009;53:2475-2482.

75. Weiss EC, Zielinska A, Beenken KE, Spencer HJ, Daily SJ, Smeltzer MS. Impact of sarA on daptomycin susceptibility of Staphylococcus aureus biofilms in vivo. Antimicrob Agents Chemother. 2009;53:4096-4102.

76. Wenke JC, Owens BD, Svoboda SJ, Brooks DE. Effectiveness of commercially-available antibiotic-impregnated implants. $J$ Bone Joint Surg Br. 2006;88:1102-1104.

77. Whelan DM, van der Giessen WJ, Krabbendam SC, van Vliet EA, Verdouw PD, Serruys PW, van Beusekom HM. Biocompatibility of phosphorylcholine coated stents in normal porcine coronary arteries. Heart. 2000;83:338-345.

78. Wilson CJ, Clegg RE, Leavesley DI, Pearcy MJ. Mediation of biomaterial-cell interactions by adsorbed proteins: a review. Tissue Eng. 2005;11:1-18.

79. Xia Z, Triffitt JT. A review on macrophage responses to biomaterials. Biomed Mater. 2006;1:R1-9.

80. Yazdi IK, Murphy MB, Loo C, Liu X, Ferrari M, Weiner BK, Tasciotti E. Cefazolin-loaded mesoporous silicon microparticles show sustained bactericidal effect against Staphylococcus aureus. J Tissue Eng. 2014;5:2041731414536573. 